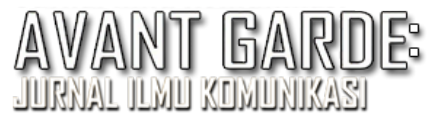

9-J5SN: 23333-430\%

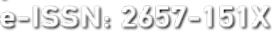

\title{
Hierarki Pengaruh Dalam Pemberitaan Gibran Sebagai Kandidat Walikota Surakarta Di Solopos.com
}

\author{
Ferri Suryo Nugroho, Pundra Rengga Andhita \\ ferrisuryo01@gmail.com,pundra@amikompurwokerto.ac.id \\ Universitas Muhammadiyah Surakarta, Jl. A. Yani, Mendungan, Pabelan, Kartasura, Sukoharjo \\ Universitas Amikom Purwokerto, Jl. Let. Jend. Pol. Soemarto, Purwokerto
}

Submitted: 25 Maret 2021, Revised: 24 April 2021, Accepted : 21 Mei 2021

\begin{abstract}
Abstrak
Pemberitaan di media massa bukanlah sesuatu yang berjalan alamiah. Ada hierarki pengaruh yang menentukan naik tidaknya berita. Meski demikian, tidak semua hierarki pengaruh berasal dari lingkungan internal media, ada pengaruh eksternal yang juga bisa menentukan berita. Inilah yang ditemukan dalam hierarki pengaruh dalam pemberitaan Gibran Rakabuming Raka di Solopos.com sebagai kandidat walikota Surakarta. Dengan menggunakan metode deskriptif kualitatif yang menitikberatkan pengumpulan data melalui wawancara mendalam, observasi dan studi literasi, hasil penelitian ini menunjukkan bahwa intensitas pemberitaan Gibran sebagai calon kandidat Walikota Surakarta di Solopos.com tidak menandakan adanya dependensi Solopos.com terhadap Gibran. Pada level individu, nilai profesionalitas jurnalis lebih dominan dibandingkan pilihan politik personalnya. Pada level rutinitas media memperlihatkan adanya tahapan yang ketat dalam pemberitaan Gibran melalui rapat redaksi dan pengawasan berjenjang. Kedua aspek ini berperan sebagai quality control terhadap produk berita yang dihasilkan Solopos.com. Untuk level organisasi memperlihatkan tidak adanya faktor internal (owner atau jejaring media grup) dan eksternal (pengiklan atau kekuatan politik) yang memengaruhi pemberitaan Gibran. Ruang redaksi tidak terintervensi oleh elit media, pemilik atau pengiklan. Pada level ekstra media lebih menekankan pada adnaya temuan mengenai perhatian masyarakat terhadap Gibran. Inilah yang menjadi pertimbangan Solopos.com untuk menjadikan pemberitaan Gibran sebagai running news. Gibran dinilai memiliki news value tinggi. Adapun level ideologi lebih menekankan pada upaya Solopos.com dalam membangun ekosistem organisasi media yang mengedepankan kualitas produk jurnalistik aktual, kredibel, informatif, edukatif, solutif dan variatif.
\end{abstract}

Kata Kunci: Gibran, hierarki pengaruh, media massa, pemilu, Solopos.

\section{The Hierarchy of Influence in Reporting on Gibran as a Candidate for Mayor of Surakarta on Solopos.com}

\begin{abstract}
News coverage in the mass media is not something that goes naturally. There is a hierarchy of influence that determines whether the news rises or not. However, not all hierarchies of influence originate from the internal environment of the media, there are external influences that can also determine the news. This is what was found in the hierarchy of influence in the coverage of Gibran Rakabuming Raka on Solopos.com as a candidate for mayor of Surakarta. By using a qualitative descriptive method that emphasizes data collection through in-depth interviews, observation and literacy studies, the results of this study indicate that the intensity of Gibran's reporting as a candidate for Mayor of Surakarta on Solopos.com does not indicate Solopos.com's dependence on Gibran. At the individual level, the professional value of journalists is more dominant than their personal political choices. At the level of
\end{abstract}


routine media, it shows that there are strict stages in Gibran's reporting through editorial meetings and tiered supervision. These two aspects act as quality control of the news products produced by Solopos.com. At the organizational level, it shows that there are no internal (owner or group media network) and external (advertisers or political power) factors that influence Gibran's news. The newsroom is not intervened by the media elite, owners or advertisers. At an extra level, the media places more emphasis on findings regarding public attention to Gibran. This is what Solopos.com takes into account in making Gibran's news running news. Gibran is considered to have high news value. The ideological level puts more emphasis on Solopos.com's efforts in building an ecosystem of media organizations that prioritizes the quality of actual, credible, informative, educational, solution and varied journalistic products.

Keywords: Gibran, hierarchy of influence, mass media, elections, Solopos

\section{PENDAHULUAN}

Perkembangan teknologi informasi telah mendorong inovasi media massa dari luring menjadi daring. Perubahan ini juga dialami media massa cetak, seperti koran. Awalnya, koran hanya tersedia dalam bentuk cetak (printed media), namun kini koran mudah ditemui dalam bentuk electronics paper (e-paper). Selain itu, distribusi berita yang ada di koran juga bisa ditemui melalui portal berita digital. Melalui portal inilah jangkauan pembaca menjadi lebih luas. Ruang ini menyediakan aliran informasi tanpa batas dan menimbulkan ketergantungan masyarakat. Informasi yang didapatkan melalui ruang ini hampir selalu menjadi acuan masyarakat untuk dikembangkan dalam kehidupan sehari-hari (Andhita, 2019).

Semangat inovasi teknologi informasi juga dilakukan koran lokal, salah satunya Solopos. Awalnya, Solopos merupakan surat kabar cetak yang beredar di Surakarta, Jawa Tengah, sejak tahun 1997. Namun tuntutan digitalisasi telah mendorong Solopos untuk melahirkan format baru, media multi platform. Sejak 9 September 2007 Solopos resmi meluncurkan Solopos.com. Melalui portal ini sebaran berita solopos menjadi lebih luas dan variatif. Seiring waktu, Solopos.com semakin mendapatkan tempat di hati pembaca, ini ditandai dengan keberhasilan Solopos.com menjadi portal berita nomor satu berbasis koran daerah berdasarkan peringkat Alexa (Solopos.com, 2019).

Peran media massa dalam menyampaikan informasi tentu memengaruhi sudut pandang khalayak dalam melihat peristiwa. Sebuah peristiwa yang dianggap penting bagi media bisa dianggap penting juga oleh masyarakat (McQuail, 2010). Dalam memproduksi berita, informasi yang telah dihimpun wartawan akan diseleksi jajaran redaksi. Gerald Kosicki menyatakan, jajaran redaksi tidak hanya mengawasi dan mengubah informasi namun juga terlibat dalam menekankan aspek tertentu dari suatu masalah (Griffin, 2012). Seleksi berita menjadi semakin ketat dalam rapat redaksi. Tentu itu perlu dilakukan karena begitu banyaknya peristiwa yang terjadi dalam periode waktu tertentu. Misal, dalam satu hari, ratusan hingga ribuan peristiwa bisa saja terjadi, kondisi itulah yang tidak memungkinkan bagi media untuk menyajikan seluruh peristiwa. Media harus memilih berita yang dianggap penting, memiliki nilai berita, nilai jual dan sesuai visi misinya. Berita yang disajikan media pada khalayak merupakan hasil komparasi dari pengaruh internal dan eksternal organisasi media (Stephen Reese, 1991). Selain faktor internal yang berkaitan dengan manajerial dan editorial, faktor eksternal seperti kekuasaan dan pengiklan juga bisa memengaruhi konten berita. Di titik inilah berita yang disajikan media bisa disinyalir tidak netral. Teks yang disampaikan oleh media 
tidak terlepas dari tujuan tertentu. Ada ideologi, nilai dan muatan pesan yang ingin disampaikan oleh media kepada masyarakat (Andhita, 2020). Lebih lanjut, teks dalam industri media bisa dinilai sebagai komoditas ekonomi politik. Biasanya, titik rawan asumsi itu muncul ketika berkaitan dengan kontestasi politik. Berita politik memiliki nilai strategis. Pemberitaan politik menjadi sarana komunikasi politik dari pihak yang berkepentingan dengan peristiwa politik (Sosiawan \& Wibowo, 2019).

Dalam kontestasi politik tidak sedikit partai politik memanfaatkan media massa untuk menyampaikan pesan politik (Rahman, 2018). Delfi menjelaskan, penggunaan media dalam kampanye politik sangat dibutuhkan kontestan politik untuk menggiring opini publik dan propaganda (Fadhlurrohman \& Purnomo, 2020). Peran tersebutlah yang menjadikan media dimanfaatkan komunikator politik guna membangun preferensi masyarakat. Politik media juga dimanfaatkan oleh politisi untuk mobilisasi dukungan masyarakat sehingga memeroleh kemenangan dalam pemilihan umum (Hajad, 2018).

Dalam penelitiannya, Fadhlurrohman dan Purnomo menunjukkan bahwa media massa sangat diandalkan dan berpengaruh untuk memenangkan kontestasi politik (Fadhlurrohman \& Purnomo, 2020). Tidak hanya media massa konvensional, calon kandidat juga memanfaatkan media daring. Ada kecenderungan kontestan politik untuk mengoptimalkan media daring. Kecenderungan ini dikarenakan jangkauan media daring yang lebih luas dibandingkan non daring. Tidak terkecuali juga pada pemilihan kepala daerah serentak tahun 2020 lalu. Beberapa daerah di Indonesia yang menyelenggarakan kontestasi politik tidak luput dari pemberitaan media, termasuk juga Kota Surakarta. Media lokal dan nasional memberikan porsi pemberitaan cukup besar pada pilkada Surakarta. Salah satu penyebabnya adalah keikutsertaan putra presiden Republik Indonesia, Gibran Rakabuming Raka dalam kontestasi calon walikota Surakarta. Pemberitaan Gibran tidak hanya menghiasi media nasional tetapi juga Solopos.com.

Solopos.com cukup banyak memberitakan Gibran. Pemberitaan sudah dimulai sejak rencana Gibran maju menjadi walikota Surakarta, kemunculan dukungan partai politik hingga keluarnya surat rekomendasi dari Partai Demokrasi Indonesia Perjuangan (PDIP). Intensitas pemberitaan Gibran di Solopos.com cukup banyak. Terhitung sejak bulan Desember 2019 sampai Juni 2020 sebanyak 174 pemberitaan mengenai Gibran telah muncul di portal berita Solopos.com. Rinciannya, sebanyak 56 berita pada bulan Desember, 25 berita pada bulan Januari, 50 berita pada bulan Februari, 11 berita pada bulan Maret, 3 berita pada bulan April, 8 berita pada bulan Mei dan 21 berita pada bulan Juni. Disinyalir, Gibran memiliki nilai berita bagi masyarakat Solo.

Di sisi lain, pemberitaan mengenai rival Gibran, Achmad Purnomo, hanya muncul sebanyak 77 berita. Adapun rinciannya sebanyak 11 berita pada bulan Desember, 10 berita pada bulan Januari, 30 berita pada bulan Februari, 3 berita pada bulan Maret, 4 berita pada bulan April, 3 berita pada bulan Mei dan 11 berita pada bulan Juni. Perbedaan kuantitas berita dari dua kandidat tersebut melahirkan spekulasi adanya kedekatan Solopos.com dengan Gibran. Ini seperti diungkapkan Quinley (2015), "Every piece of writing is written for a reason" (Andhita, 2021). Selain Gibran dan Purnomo, Solopos.com juga memberikan porsi pemberitaan pada Bagyo Wahyono, calon walikota Surakata yang berasal dari jalur independen. Namun pemberitaan Bagyo muncul lebih sedikit, hanya 19 berita dengan rincian 12 berita pada bulan Januari dan 4 berita pada bulan Juni. Kemudian jika dikomparasikan 
dengan media lain, seperti radarsolo.jawapos.com, jumlah pemberitaan Gibran terkait pencalonan dirinya sebagai walikota Surakarta juga tidak sebanyak solopos.com. Pada rentang waktu yang sama pemberitaan Gibran di radarsolo.jawapos.com hanya ada 50 berita.

Intensitas pemberitaan bisa menandakan adanya kedekatan media dengan kontestan politik. Kedekatan itu yang berpotensi memunculkan eksklusivitas, adanya ruang lebih pada pemberitaan media. Ini yang sulit dihindari pada tahun politik. Kontestan politik dan media berpotensi memiliki hubungan tertentu yang bisa memengaruhi pemberitaan. Hal ini pernah diungkapkan Milojevic \& Krstić melalui penelitiannya, "Hierarchy of influences on transitional journalism - Corrupting relationships between political, economic and media elites" memaparkan bahwa peran media dalam masa transisi politik di Serbia memperlihatkan jauhnya praktik jurnalisme dari profesionalitas dan kode etik jurnalistik. Ancaman, tekanan dan praktik korupsi yang terjadi antara pekerja media dengan aktor politik, elit media dan ekonomi memengaruhi iklim kebebasan pers. Adanya hubungan politisi, iklan, elite dan negara dengan media menjadikan media di Serbia tidak memiliki otonomi selama masa transisi (Milojevic \& Krstić, 2018). Hal senada juga bisa ditemui dari penelitian Nashrudin yang menunjukkan bahwa dalam kontestasi politik di Provinsi Banten, independensi dan netralitas Radar Banten patut dipertanyakan. Nashrudin menilai adanya praktik ekonomi politik pada media yang memengaruhi pemberitaan (Nashrudin, 2017).

Telaah teori yang bisa digunakan untuk mengetahui hierarki pengaruh dalam pemberitaan adalah teori hierarki pengaruh yang dicetuskan Shoesmaker \& Resse. Asumsi teori ini terdiri dari lima level pengaruh yang tersusun dari individual level, media routines level, organizational level, extra media level dan ideology level (Shoemaker \& Reese, 1996). Level individu mengarah pada latar belakang personal pekerja media yang dapat memengaruhi isi pemberitaan. Ada tiga faktor yang melatarbelakangi pekerja media memengaruhi isi pemberitaan. Pertama, faktor karakteristik dan latar belakang (jenis kelamin, etnis, orientasi seksual, pendidikan dan status sosial). Kedua, faktor pengalaman pribadi seperti keyakinan, sikap politik dan nilai. Ketiga ,berkaitan dengan peran profesional dan etika pekerja media. Level kedua, rutinitas media berkaitan dengan pola perilaku rutin yang dilakukan media dalam pemberitaan. Rutinitas media memiliki tiga unsur yakni, sumber berita (suppliers), masyarakat (consumers) dan organisasi media (processor).

Level ketiga adalah organisasi media. Level ini berkaitan dengan kebijakan dan struktur organisasi media. Kebijakan dan pemegang kekuasaan tertinggi media berpengaruh terhadap berita. Pemilik atau eksekutif tertinggi memiliki keputusan akhir tentang apa yang dilakukan organisasi media (Shoemaker \& Reese, 1996). Level keempat, extra media, berkaiatan dengan faktor yang berasal dari luar organisasi seperti sumber informasi, kelompok kepentingan, pengiklan, audience (masyarakat), pemerintah dan teknologi. Level terakhir yang memengaruhi isi media adalah ideologi. Menurut Williams, ideologi adalah sistem makna, nilai dan keyakinan. Level ini paling makro dalam model hierarki pengaruh isi media (Shoemaker \& Reese, 2013). Melalui pemahaman lima level tersebutlah penelitian ini ingin melihat bagaimana hierarki pengaruh dalam pemberitaan Gibran Rakabuming Raka di Solopos.com sebagai calon kandidat walikota Surakarta. 


\section{METODE PENELITIAN}

Penelitian ini menggunakan metode deskriptif kualitatif, menekankan penjelasan fenomena secara rinci melalui pengumpulan data yang membedakannya dengan fenomena lain (Sandu \& Ali, 2015). Populasi penelitian ini merupakan pekerja media di jajaran redaksi Solopos.com. Adapun sampelnya ditentukan melalui kriteria tertentu yang relevan. Hasil penarikan sampel yang akan dijadikan sumber data dalam penelitian ini. Sumber data terdiri dari dua jenis, yakni, primer dan sekunder. Data primer diperoleh melalui wawancara dan observasi. Untuk wawancara dilakukan dengan memilih kriteria relevan dari populasi yang ada. Kriteria tersebut adalah jajaran redaksi di Solopos.com. Dari populasi tersebut penulis tentukan sampelnya sebanyak dua orang yakni Danang Nur Ihsan (Redaktur Pelaksana Digital) dan Kurniawan (Jurnalis Solopos.com). Stokes (2006) mengatakan, dalam wawancara mendalam, penentuan jumlah narasumber diambil berdasarkan kriteria kelayakan dan kompetensinya. Ini senada dengan apa yang dikatakan Bernard (1998) bahwa penentuan narasumber bukan atas dasar keterwakilan (Syahputra, 2017). Adapun untuk observasi dilakukan dengan cara kunjungan media serta melakukan pengamatan pada portal berita Solopos.com dalam rentang waktu tertentu. Sedangkan data sekundernya lebih menekankan studi literasi. Data yang diperoleh melalui tiga teknik pengumpulan tersebut akan dikumpulkan, dikategorisasikan lalu disajikan secara deskriptif.

\section{HASIL DAN PEMBAHASAN}

Dalam teori hierarki pengaruh, level individual disinyalir bisa memengaruhi isi pemberitaan. Tiap pekerja media mulai dari wartawan, redaktur, hingga pemimpin redaksi memiliki pandangan personal terhadap peristiwa tertentu. Pandangan ini tidak bisa lepas dalam diri mereka ketika menyusun berita. Hanya saja pandangan tersebut seharusnya ditempatkan dalam porsi yang tepat dan objektif. Ini penting karena teks yang disampaikan oleh media tidak terlepas dari tujuan tertentu. Ada ideologi, nilai dan muatan pesan yang ingin disampaikan oleh media kepada masyarakat (Andhita, 2020). Begitu pula dalam pemberitaan pencalonan Gibran Rakabuming Raka sebagai walikota Surakarta di Solopos.com. Redaktur Pelaksana Digital Solopos.com, Danang Nur Ihsan mengungkapkan, "Wartawan memiliki peran dalam penentuan konten berita. Wartawan diberikan kebebasan dalam membuat atau mengembangkan berita. Ketika redaktur setuju, maka tidak ada masalah (Danang, wawancara, 11 September 2020). Kebebasan mengembangkan berita termasuk juga soal sudut pandang berita. Jadi, sudut pandang tidak terlepas dari pengetahuan, wawasan dan sikap personal wartawan dalam melihat peristiwa. Ini seperti diungkapkan Kurniawan, wartawan Solopos.com, "Sudut pandang wartawan dipengaruhi wawasan, pengetahuan dan pengalamannya. Hal tersebut memengaruhinya dalam menulis berita. Termasuk faktor adaptasi terhadap nilai berita dan tingkat keterbacaan berita. Adaptasi terhadap apa yang saat ini sedang menjadi perhatian pembaca atau netizen" (Kurniawan ,wawancara, 14 September 2020).

Namun untuk preferensi politik pribadi, wartawan Solopos.com tetap mengedepankan profesionalitas. Hal itu telah ditanamkan sejak dini oleh pimpinan Solopos.com kepada semua wartawan ketika baru bergabung di Solopos. Pilihan politik tidak memengaruhi pemberitaan di Solopos.com, "Saya punya preferensi politik terhadap seseorang tapi itu tidak boleh memengaruhi berita. Itu menjadi kesadaran bersama" (Danang, wawancara, 11 September 
2020). Kesadaran tersebut ditekankan oleh semua pekerja media. Kesadaran internal dalam diri wartawan untuk mengesampingkan preferensi politik pribadi sangat penting demi menjaga netralitas berita. "Preferensi politik bukan parameter dalam membuat berita. Hal yang menjadi perhatian justru muatan yang menjadi perhatian dan disukai masyarakat. Itu yang menjadi acuan, bukan preferensi politik" (Kurniawan, wawancara, 14 September 2020)

Adanya kesadaran internal juga tidak terlepas dari peran organisasi Solopos.com dalam memberikan regulasi tegas bagi pekerjanya. Solopos.com melarang pekerjanya bergabung menjadi anggota atau simpatisan partai politik. Ini dilakukan untuk menghindari konflik kepentingan. "Hal itu bisa memengaruhi netralitas dan sudut pandang penulis berita" (Kurniawan, wawancara, 14 September 2020). Kontrol organisasi juga dilakukan dengan simultansi transfer pengetahuan mengenai kode etik dan regulasi lain terkait pemberitaan. "Menjadi wartawan di Solopos itu bukan hanya soal kemampuan menulis tetapi juga penerapan dan pemahaman mengenai regulasi. Solopos senantiasa memberikan transfer knowledge terkait kode etik wartawan dan regulasi lain" (Kurniawan, wawancara, 14 September 2020). Semua aspek tersebut memengaruhi kredibilitas wartawan Solopos.com sebagai pekerja media yang mengedepankan profesionalitas.

Level rutinitas media berkaitan dengan pola perilaku yang secara rutin dilakukan media dalam mengemas pemberitaan. Dalam rutinitas media terdapat tiga unsur yakni, sumber berita (suppliers), audiens/masyarakat (consumers), organisasi media (processor). Sumber berita yang didapatkan Solopos.com tidak hanya mengandalkan wawancara langsung dengan subjek berita tetapi juga mengedepankan riset. Hal ini yang dilakukan wartawan Solopos.com terkait pemberitaan Gibran sebagai calon walikota Surakarta. Ada riset yang telah dilakukan sebelumnya seperti, mengamati kontestasi politik nasional, diskusi internal di meja redaksi, komparasi sumber data, melihat survei elektabilitas calon hingga mengartikulasikan suara masyarakat di tingkat grassroot.

Terkait intensitas pemberitaan Gibran yang tinggi, ini tidak terlepas dari pandangan Solopos.com terhadap sosok Gibran yang dinilai memiliki news value. Solopos.com melihat ada perhatian pembaca yang cukup besar pada pemberitaan Gibran. "Jadi ketika nama Gibran muncul hampir selalu diminati pembaca. Kita tahu berapa banyak rata-rata pembaca berita Gibran. Dari sinilah topik ini menjadi perhatian" (Danang, wawancara, 11 September 2020).

Level organisasi media menitikberatkan pada pengaruh organisasi media terhadap konten pemberitaan. Ini tidak terlepas dari pemahaman bahwa pemegang kekuasaan tertinggi media sangat berpengaruh terhadap konten pemberitaan. Pemilik media atau eksekutif tertinggi memiliki keputusan akhir tentang apa yang dilakukan organisasi (Shoemaker \& Reese, 1996). Tidak bisa dipungkiri, tingginya intensitas pemberitaan Gibran bisa memunculkan asumsi dependensi Solopos.com. Apalagi jika melihat keberadaan Solopos.com yang merupakan bagian dari Solopos, sebuah jejaring media yang kepemilikannya tidak terlepas dari Bisnis Indonesia Grup.

Namun Solopos.com memastikan tidak ada intervensi terhadap ruang redaksi yang bisa memengaruhi pemberitaan. Hal tersebut didukung dengan tidak adanya kedekatan personal antara elit Solopos dengan Gibran. "Ini berkaitan dengan independensi media dan redaksi. Independensi tidak hanya berlaku terhadap lingkungan internal tetapi juga eksternal. Bukan hanya konteks pilkada tetapi juga lainnya" (Kurniawan, wawancara, 14 September 2020). 
Selain itu, Solopos.com juga memastikan adanya sterilisasi ruang redaksi dari pengaruh tertentu. "Redaksi ibarat ruang suci yang tidak bisa diakses kekuatan manapun, kekuatan eksternal (pengiklan atau kekuatan politik di Solo) ataupun internal, seperti owner dan lainnya" (Kurniawan, wawancara, 14 September 2020). Ada upaya dari jajaran redaksi untuk menjaga independensi. Berita yang ada merupakan komparasi riset internal, observasi lapangan dan news value. Namun, redaksi tetap membuka ruang untuk berbagai masukan terkait pengembangan konten tanpa memengaruhi keputusan akhir pemberitaan.

Level extra media berkaitan dengan faktor luar organisasi media yang memengaruhi konten pemberitaan seperti sumber berita, kelompok kepentingan, pengiklan, audience (masyarakat), pemerintah dan teknologi. Dalam konten pemberitaan di Solopos.com, pengiklan memang dapat memengaruhi konten, hanya saja jika itu bersifat advertorial, brand content atau korporatorial. Iklan yang bersifat kontraktual memberikan space bagi pemesan untuk membuat konten sesuai kehendaknya, namun tidak keluar dari norma jurnalistik. "Kalau pemberitaan secara langsung tentu tidak. Tetapi dalam konteks pasang iklan (brand content) itu soal lain. Biasanya kita berikan kode BC" (Danang, wawancara, 11 September 2020). Hal senada juga diungkapkan wartawan Solopos.com, "Bisa dalam bentuk berita advertorial, tetapi juga ada keterangannya (advertorial) dan itu sebatas kerja sama profesional" (Kurniawan, wawancara, 14 September 2020)

Solopos.com menyebutkan pemisahan konten berita murni dengan advertorial dengan istilah "garis api". Sebuah garis pemisah tegas antara konten berita murni dengan iklan. Bahkan, ruang yang tersedia bagi pengiklan juga terikat norma jurnalistik. Ada pakem yang menjadi acuan bersama. "Kita berikan ruang bagi pengiklan namun tetap dibatasi norma jurnalistik" (Kurniawan, wawancara, 14 September 2020). Terkait pemberitaan Gibran sebagai calon kandidat walikota Surakarta, Solopos.com memastikan hal tersebut merupakan konten berita. Tidak ada kerja sama advertorial antara Gibran dengan Solopos.com.

Solopos.com sebagai perusahaan media memiliki pandangan, pedoman atau ideologi dalam mengimplementasikan praktik jurnalistiknya. Level ideologi Solopos.com ditunjukkan melalui visi misi Solopos. Visi misi diturunkan menjadi tagline "Meningkatkan Dinamika Masyarakat." Melalui tagline tersebut Solopos.com berupaya membangun atmosfir produksi konten berita yang bermanfaat, dinamis, solutif dan mencerahkan masyarakat namun tetap sesuai kaidah jurnalistik. Penerapan kaidah jurnalistik merupakan pedoman utama yang menjadi acuan dalam produksi konten berita. Terkait penonjolan aspek tertentu tidak terlepas dari bagaimana Solopos.com menilai konten yang disukai masyarakat. Tipologi konten inilah yang menjadi perhatian Solopos.com untuk memberikan intensitas pemberitaan lebih banyak dibandingkan lainnya. Kita menyesuaikan diri dengan tren. Kita memahami keinginan pembaca. Kita pertahankan konten yang disukai pembaca" (Kurniawan, wawancara, 14 September 2020)

Terkait pemberitaan Gibran sebagai calon walikota Surakarta di Solopos.com menunjukkan bahwa media ini mengedepankan news value dan pembacanya. Kedua hal tersebut yang ditekankan jajaran redaksi Solopos.com sehingga membuat topik ini menjadi running news, sebuah berita berkesinambungan dengan unsur kebaruan. Salah satu pertimbangannya adalah adanya dinamika politik yang cukup menarik di Surakarta. Gibran sebagai putra presiden RI berkompetisi dengan kader senior untuk mendapatkan surat 
rekomendasi dari partai pengusung yang sama. Pandangan tersebut tidak terlepas dari kejelian wartawan Solopos.com yang bisa memprediksikan keberlangsungan topik ini akan menarik perhatian masyarakat. Ini yang mendorong topik Gibran menjadi running news. Kejelian wartawan bisa dipengaruhi dari komparasi memadai antara pendidikan, pengalaman dan latar belakang. Ketiganya dapat memengaruhi cara wartawan dalam memandang dunia sehingga berdampak luas terhadap apa yang mereka pilih untuk disampaikan kepada pembaca (Shoemaker \& Reese, 1996). Adapun faktor yang sangat berperan dalam membangun sensitivitas terhadap topik pemberitaan adalah pengalaman wartawan. Faktor ini yang mengasah kejelian wartawan. Pengalaman bisa menjadi salah satu faktor yang memengaruhi wartawan dalam mengambil keputusan. Hal ini bisa menepis anggapan bahwa individu (wartawan) sepenuhnya dikendalikan oleh rutinitas perusahaan (McEntee, 2018).

Di sisi lain, sikap politik pekerja media juga bisa menjadi faktor yang memengaruhi pemberitaan (Shoemaker \& Reese 1996). Namun hal tersebut tidak terjadi di Solopos.com. Media ini memastikan preferensi politik individual tidak memengaruhi intensitas pemberitaan Gibran. Apalagi Solopos.com menerapkan prinsip gatekeeping yang teratur antar jajaran. Prinsip ini mampu mengontrol profesionalitas pekerja. Untuk memastikannya terlaksana, Solopos.com senantiasa menanamkan nilai profesionalitas bagi pekerjanya. Doktrinasi berjalan simultan, sejak awal bekerja hingga sekarang. Pakem yang mendasari wartawan Solopos.com adalah kaidah jurnalistik. Kaidah inilah yang menjadi acuan semua wartawan di Solopos.com. Dependensi pilihan politik personal telah ditegaskan tidak boleh ada dalam pemberitaan. Ketegasan ini bahkan sudah dipreventifkan sejak awal. Ada larangan dari organisasi Solopos.com agar pekerjanya tidak bergabung atau menjadi simpatisan partai politik. Ini penting karena partisipasi pekerja media dalam partai politik akan memengaruhi netralitasnya. Jan Brant mengatakan, ketika jurnalis sangat terlibat dalam peran politik hal tersebut akan merusak kredibilitas surat kabar (Shoemaker \& Reese, 1996). Pemahaman ini yang menjadi pertimbangan Solopos.com untuk menjaga kredibilitasnya sebagai lembaga pers. Lebih lanjut, intensitas pemberitaan Gibran di Solopos.com sebagai kandidat walikota Surakarta yang lebih banyak dibandingkan kandidat lain tidak menandakan adanya dependensi wartawan terhadap Gibran. Banyaknya intensitas pemberitaan tersebut tidak terlepas dari news value Gibran yang menarik perhatian pembaca.

Faktor lain yang berpengaruh dalam level individu wartawan Soloposcom adalah profesionalisme dan kode etik. Adanya simultansi transfer knowledge mengenai kode etik dan profesionalisme telah mendukung terciptanya pemahaman merata pada pekerja Solopos.com. Hal itu dijewantahkan melalui pelatihan berjenjang dalam rentang waktu tertentu. Pelatihan akan mengasah profesionalisme wartawan. Mereka akan lebih mementingkan profesionalisme dibandingkan keyakinan pribadi (Abiwu, 2019). Jadi, kebebasan wartawan dalam menentukan pemberitaan tidak membuatnya melepaskan etika profesi jurnalis. Ini penting guna menghasilkan produk jurnalisme berkualitas, di mana jurnalisme bertumpu pada nilai faktualitas, tidak berpihak, tidak komersial dan sensasional (Shim, 2016).

Untuk level rutinitas media di Solopos.com berkaitan dengan adanya kegiatan rutin yang dilakukan organisasi media untuk menjaga quality control konten pemberitaan. Salah satu caranya melalui gelaran rapat rutin jajaran redaksi. Rapat ini menjadi forum check and balances sebelum topik diputuskan naik menjadi berita. Sebuah berita yang naik di 
Solopos.com bukan hasil produksi individu tetapi ada peran jajaran lain. Dari wartawan, tulisan akan diberikan pada editor. Di tahap ini editor dapat merubah sudut pandang tulisan namun tetap mengedepankan koordinasi dengan wartawan untuk menghindari miskomunikasi. Jadi, banyaknya pemberitaan Gibran di Solopos.com sudah melalui pola pengawasan berjenjang antar staf redaksi. Kontrol berjenjang inilah yang bisa menutup celah subjektifitas wartawan dalam memberitakan Gibran sebagai calon walikota Surakarta.

Hal lain yang dilakukan Solopos.com dalam menjaga level rutinitas media adalah sumber berita. Solopos.com menekankan wartawannya agar tidak tidak terjebak dalam mindset usang, di mana sumber berita hanya diperoleh dari wawancara dan observasi saja. Solopos.com mengharuskan semua wartawannya untuk mengedepankan tiga cara pemerolehan sumber berita yakni komparasi antara wawancara, observasi dan riset data melalui berbagai open source. Keberadaan riset data sangat penting guna mendapatkan variasi dalam sudut pandang pemberitaan. Ke depan konsep jurnalisme tidak bisa hanya mengandalkan wawancara dan observasi, namun juga memerlukan data. Penggunaan data yang valid dapat menjadi fakta kuat dalam berita (Asprilla \& Maharani, 2019). Kemudian, selain mempertimbangkan kriteria, kompetensi dan relevansi dalam pemilihan narasumber, Solopos.com juga menekankan perlunya menerapkan sikap disiplin dalam verifikasi informasi. Semua wartawan wajib melakukan verifikasi terhadap narasumber, baik itu yang bersumber dari pernyataan langsung ataupun riset data berbasis open source. Kovach dan Rosenstiel menyebutkan, disiplin verifikasi merupakan satu dari sepuluh elemen jurnalisme yang perlu diterapkan wartawan dalam membuat berita. Disiplin verivikasi inilah yang membedakan produk jurnalisme dengan non jurnalisme (Andhita, 2019).

Faktor lain yang diperhatikan Solopos.com dalam level rutinitas media adalah masyarakat. Staf redaksi Solopos.com senantiasa memperhatikan tingkat keterbacaan topik pemberitaan. Salah satunya dilihat dari jumlah perhatian masyarakat yang bisa dipantau melalui traffic website. Masyarakat adalah kunci, apa yang ramai dibicarakan masyarakat di dunia maya adalah topik yang akan ramai dan mendapat tanggapan yang baik (Kaban, 2017). Selain memantau traffic website, cara lain yang digunakan Solopos.com untuk mengetahui apa yang sedang menjadi perbincangan masyarakat melalui social media. Melalui saluran ini Solopos.com bisa melihat sejauh mana topik Gibran sebagai calon walikota Surakarta menjadi perbincangan netizen. Ketika suatu konten dapat menarik banyak audience, maka konten tersebut akan ditindaklanjuti oleh organisasi jurnalistik (Ferrucci, 2018).

Solopos.com menemukan indikasi bahwa personality Gibran memiliki magnet tersendiri bagi netizen. Ini yang membuat topik Gibran senantiasa menjadi perhatian masyarakat. Banyaknya perbincangan mengenai Gibran di social media menandakan pembaca senantiasa ingin mencari informasi mengenai Gibran. Inilah yang juga mendasari Solopos.com menjadikan topik Gibran sebagai running news. Masyarakat (netizen ataupun citizen) menjadi faktor utama dibalik pemberitaan Gibran yang cukup banyak di Solopos.com.

Untuk level ketiga, organisasi media, meski Solopos.com merupakan bagian Solopos, jejaring Bisnis Indonesia Grup, tidak menjadikan pengambilan keputusan pemberitaan berada di luar rapat redaksi. Upaya ini dilakukan untuk menghindari campur tangan pemilik pada konten berita. Ini penting karena campur tangan pemilik media terhadap pemberitaan memungkinkan terjadinya Berlusconi Syndrom (Istilah yang merujuk pada dominasi pemilik 
media di Italia) terhadap media tersebut. Dalam kondisi tersebut posisi wartawan rentan, bisa tidak lagi memenuhi kebutuhan publik melainkan pemilik media sesuai sikap politiknya (Milojević \& Krstić, 2018). Lebih lanjut, Berlusconi Syndrom tidak terjadi di Solopos.com. Semua keputusan final pemberitaan berada di rapat redaksi dan tidak boleh diganggu pengaruh eksternal atau internal. Rapat redaksi memberikan kebebasan pada wartawan Solopos.com untuk memberikan sudut pandang pemberitaan dengan tone positif, negatif atau netral asalkan mengedepankan unsur faktualitas. Shoemaker dan Reese menegaskan, pemberian garis pembatas antara profesionalisme dan kepentingan organisasi adalah salah satu tanggung jawab media dengan tujuan meminimalkan gangguan komersial kepada profesionalisme media (Christian, 2019).

Meski pemahaman tersebut berbanding terbalik dengan yang diungkapkan McQuail, institusi media harus dinilai sebagai bagian dari sistem ekonomi politik yang mana produk jurnalistik tidak bisa lepas dari mekanisme kerja pasar media (Andhita, 2018). Namun dalam konteks pemberitaan Gibran di Solopos.com tidak memperlihatkan adanya pengaruh faktor internal dan eksternal. Salah satu indikasinya adalah tidak adanya jalinan kerja sama advertorial antara Gibran dengan Solopos.com. Seandainya ada, juga tidak akan memengaruhi konten berita. Sebaliknya, rival Gibran, pasangan Bagyo-Suparjo justru telah menjalin kerja sama advetorial di Solopos. Meski demikian itu juga tidak memengaruhi kaidah jurnalitsik yang diterapkan Solopos.com. Ini persis seperti yang diungkapkan Kovach \& Rosentiel bahwa loyalitas jurnalisme terletak pada khalayak, bukan pada pemerintah, pengiklan atau perusahaan media mereka (Wijaya, 2019).

Level terakhir yang memengaruhi isi pemberitaan adalah ideologi. Meskipun tidak memiliki pengaruh secara langsung, level ini memiliki pengaruh dominan dibandingkan lainnya (Tawaang \& Imran, 2017). Pada Solopos.com, ideologi media dapat ditunjukkan melalui visi, misi dan tagline. Ideologi media dapat dipahami sebagai gagasan atau nilai pokok yang diusung media massa melalui pesan yang disampaikan kepada khalayak (Pawito, 2014). Dengan mengangkat tagline "Meningkatkan Dinamika Masyarakat," Solopos.com berusaha merangkul semua pihak untuk menyajikan berita kredibel bagi masyarakat yang produksinya memperhatikan kaidah jurnalistik. Melalui upaya tersebut, Solopos.com berharap dapat memberikan kontribusi positif dalam menciptakan dinamisasi masyarakat. Dalam konteks pemberitaan Gibran, wartawan Solopos.com mengambil peran menyiarkan dan menyampaikan apa yang terjadi di masyarakat. Solopos.com menilai ada perhatian masyarakat yang cukup besar terhadap Gibran. Masyarakat cenderung positif menyambut Gibran maju dalam kontestasi politik di Kota Surakarta. Hal ini senada dengan survei dari Media Survei Nasional (Median) pada Desember 2019, masyarakat menyambut positif atas majunya Gibran dalam pemilihan walikota Surakarta. Masyarakat seakan menaruh harapan kepada Gibran untuk bisa seperti ayahnya yang pernah sukses memimpin Kota Surakarta (Miftahulhayat, 2019).

\section{UCAPAN TERIMA KASIH:}

Penulis mengucapkan terima kasih kepada Program Studi Ilmu Komunikasi Universitas Muhammadiyah Surakarta atas dukungan terhadap penyusunan artikel ini. Penulis juga mengucapkan terima kasih kepada tim redaksi jurnal Avant Garde dan reviewer atas masukan yang telah diberikan dalam penyusunan artikel ini. 


\section{SIMPULAN}

Pemberitaan Gibran sebagai kandidat walikota Surakarta di Solopos.com terlihat lebih banyak dibandingkan kompetitornya yakni, sebanyak 174 berita. Jumlah berita tersebut lebih besar jika dibandingkan dua kandidat lain, Achmad Purnomo (77 berita) dan Bagyo Wahono (19 berita). Namun banyaknya pemberitaan Gibran tidak memperlihatkan adanya kedekatan politik antara wartawan dan Gibran. Solopos.com menekankan prinsip profesionalitas sesuai kaidah jurnalistik. Prinsip itu diterapkan baik pada level institusional ataupun personal. Sementara itu, level rutinitas Solopos.com dilakukan melalui penerapan quality control yang disiplin, mulai dari rapat redaksi, proses gatekeeping yang simultan dan transfer knowledge, pelatihan memadai dan pengawasan ketat terhadap implementasi profesionalisme pekerja. Di tahap inlah Solopos.com berhasil membangun ekosistem organisasi media profesional. Pada level extra media, perhatian masyarakat menjadi faktor paling kuat yang memengaruhi pemberitaan Gibran di Solopos.com. Berita Gibran memperlihatkan traffic website dan respon netizen yang cukup baik. Dalam tahap inilah Solopos.com menangkap apa yang ada di masyarakat. Lebih lanjut pemberitaan Gibran dikembangkan sebagai running news.

Di sisi sebaliknya, pemilik media dan pengiklan terlihat tidak bisa intervensi keputusan redaksi. Independensi Solopos.com terhadap pemberitaan Gibran juga bisa dilihat dari tidak adanya kerja sama advertorial antara Gibran dan Solopos.com. Kemudian pada level ideologi, Solopos.com menjunjung tinggi kode etik jurnalistik yang ditanamkan pada pekerjanya. Besarnya intensitas pemberitaan dikarenakan adanya news value yang dimiliki Gibran. News value tersebut mendorong pembaca untuk ingin tahu lebih jauh tentang Gibran. Jadi, banyaknya pemberitaan Gibran sebagai kandidat Walikota Surakarta di Solopos.com tidak dapat dikatakan karena dependensi. Varian tone pemberitaan yang disajikan Solopos.com, baik itu tone positif, negatif atau netral menunjukkan keberimbangannya pada topik tersebut. Selain itu, independensi juga diperlihatkan Solopos.com dengan adanya space pemberitaan bagi kontestan politik lain.

\section{DAFTAR PUSTAKA}

Andhita, P. R. (2021). Pendampingan Penulisan Opini Media Daring pada PC IMM Banyumas dengan Pendekatan Group Achievement. Warta LPM, 24(2), 230-238.

Arafat, G. Y., \& Rahmah, N. A. (2019). Media Politik: Sarana Pendongkrak Elektabilitas Sebagai Strategi Pemenangan Pemilu. Alhadharah: Jurnal Ilmu Dakwah, 18(1), 91. https://doi.org/10.18592/alhadharah.v18i1.2994

Asprilla, A., \& Maharani, N. (2019). Jurnalisme Data Dalam Digitalisasi Jurnalisme Investigasi Tempo. Jurnal Kajian Jurnalisme, 3(1), 212-224. https://doi.org/10.24198/kj.v3i1.21362

Christian, J. (2019). Penerapan Prinsip Pagar Api oleh Metro TV pada Talk Show Economic Challenges. 1-19.

Fadhlurrohman, M. I., \& Purnomo, E. P. (2020). The role of online mass media as a tool for the 2019 political campaign in Indonesia. 4(July), 311-325. https://doi.org/10.25139/jsk.v4i2.2182

Fariz, L. N., \& Andhita, P. R. (2020). WACANA EKOFEMINISME TIRTO. ID. Jurnal 
Common, 4(2), 144-160.

Ferrucci, P. (2018). Networked: Social media's impact on news production in digital newsrooms. Newspaper Research Journal, 39(1), 6-17. https://doi.org/10.1177/0739532918761069

Griffin, E. (2012). In A First Look At Communi cation Theory (p. eight edition). Amerika: McGrew Hill.

Hajad, V. (2018). MEDIA DAN POLITIK ( Mencari Independensi Media Dalam Pemberitaan Politik ). 1-10.

Idris, M., \& Syaifullah. (2020). PENERAPAN KODE ETIK JURNALISTIK PADA PEMBERITAAN PEMILIHAN WALIKOTA MAKASSAR TRIBUNNEWS.COM. PENERAPAN KODE ETIK JURNALISTIK PADA PEMBERITAAN PEMILIHAN WALIKOTA MAKASSAR TRIBUNNEWS.COM, 18(1), 79-88.

Kaban, V. (2017). Proses Gatekeeping pada Tim Digital Kompas TV. Jurnal Ilmu Komunikasi ULTIMACOMM, 9(2), 46-67.

KPI. (2013). Media dan Partisipasi Pemilih. 30 Oktober, http://www.kpi.go.id/index.php/id/umum/24-dunia-penyiaran/31679-media-danpartisipasi-pemilih._Diakses pada 9 April 2020.

Kriyantono, Rachmat. 2006. Teknik Praktis Riset Komunikasi. Edisi I. Jakarta: Kencana.

Kumah-abiwu, F. (2019). Media Gatekeeping and Portayal of Black Men in America. 1-18. https://doi.org/10.1177/1060826519846429

Lighare, Dennis. (2019). Gatekeeping in the Wake of New Madia. 25 Februari, https://medium.com/tunapanda-institute/gate-keeping-in-the-era-of-new-media3585251d0743. Diakses pada 9 April 2020.

Lin, L. C. S. (2016). Convergence in election campaigns: The frame contest between Facebook and mass media. Convergence, 22(2), 199-214. https://doi.org/10.1177/1354856514545706

McEntee, R. S. (2018). Future Photographs of U.S. Women in Combat: Gatekeeping and hierarchy of influences. Journalism Practice, 12(1), 32-55. https://doi.org/10.1080/17512786.2017.1279024

McQuail, D. (2010). McQuail's Mass Communication Theory. Netherlands: SAGE Publications, Ltd.

Milojević, A., \& Krstić, A. (2018). Hierarchy of influences on transitional journalism Corrupting relationships between political, economic and media elites. European Journal of Communication, 33(1), 37-56. https://doi.org/10.1177/0267323117750674

Muhammad, B. (2017). Hirarki Pengaruh Media Dalam Pemberitaan Aksi Terorisme Di Sarinah Pada Harian Umum Republika (Bachelor's thesis, UIN Syarif Hidayatullah Jakarta: Fakultas Ilmu Dakwah dan Ilmu Komunikasi, 2017).

Nashrudin, A. (2017). Ekonomi Politik Media : Pada Pemberitaan Pemilukada Banten 2011 OLeh Radar Banten. Jurnal Informasi Universitas Negeri Yogyakarta, Desember 2016, $155-168$

Pawito, P. (2014). Meneliti Ideologi Media : Catatan Singkat. Profetik, 7(1), 5-14.

Priatna, A. N. (2017). Political Economics Media: At The Banten Selection Of 2011 By Radar Banten And Baraya Tv. Komuniti: Jurnal Komunikasi dan Teknologi Informasi, 9(1), 
$25-43$

Pundra Rengga, A (2019). Sporadisme Produk Non Jurnalisme. Detik.com, 15 Januari, https://news.detik.com/kolom/d-4385284/sporadisme-produk-non-jurnalisme. Diakses 8 November 2020.

Pundra Rengga, A. (2019). Whatsapp, Hoaks dan Early Adopter. 29 Mei, https://news.detik.com/kolom/d-4569525/whatsapp-hoaks-dan-early-adopter, diakses 8 November 2020

Pundra Rengga, A. (2018). Ekonomi Politik Media : Tentang Raja dan Ratu. 4 Februari, Radar Banyumas.

Rahman, F. A., Rouf, M. F., Asyahidda, F. N., \& Hufad, A. (2018). BIAS POLITIK DIBALIK SEBUAH MEDIA : RELEVANSI SOSIALISASI POLITIK DI INDONESIA. 8(2), $553-561$.

Rico Marbun : Masyarakat Solo Berharap Gibran seperti Jokowi. 16 Desember, https://www.jawapos.com/nasional/pemilihan/16/12/2019/rico-marbun-masyarakatsolo-berharap-gibran-seperti-jokowi/._Diakses pada 15 April 2020.

Rini Yustiningsih (2019). Solopos Digital Media, Kian Vital di Era Multiplatform. 19 September, $\quad$ https://www.solopos.com/solopos-digital-media-kian-vital-di-eramultiplatform-1019337. Diakses pada 17 September 2020.

Saraswati, M. S. (2018). Social Media and the Political Campaign Industry in Indonesia. Jurnal Komunikasi Ikatan Sarjana Komunikasi Indonesia, 3(1). https://doi.org/10.25008/jkiski.v3i1.124

Setiawati, T. (2019). Pemilu Legislatif DKI Jakarta dalam Paparan Media Daring: Analisis Isi Pemberitaan Caleg Dapil I, II, dan III Jakarta pada Pemilu 2019. Jurnal Komunikasi, 13(2), 165-178.

Setyabudi, W. A. (2018). Kebijakan Redaksional Tribunstyle. com Dalam Menentukan Berita Yang Layak (Doctoral dissertation, Universitas Muhammadiyah Surakarta).

Shim, K. (2016). Subjectivity in media source perception: Fox news versus NPR. Journal of Applied Journalism \& Media Studies, 5(2), 177-197. https://doi.org/10.1386/ajms.5.2.177_1

Shoemaker, P. J., \& Reese, S. D. (2013). Mediating the message in the 21 st century: A media sociology perspective. In Mediating the Message in the 21st Century: A Media Sociology Perspective. https://doi.org/10.4324/9780203930434

Shoemaker, P. J., \& Tim P, V. (2009). Gatekeeping Theory. Routledge.

Shoemaker, P. J., \& Reese, S. D. (1996). Mediating the Message: Theories of Influences on Mass Media Content. https://doi.org/10.1177/1326365X14540245

Siyoto, Sandu dan Ali Sodik.2015.Dasar Metodologi Penelitian.Yogyakarta:Literasi Media Publishing.

Sosiawan, Edwi Arief \& Wibowo, Rudi. (2019). Kontestasi Berita Hoax Pemilu Presiden Tahun 2019 di Media Daring dan Media Sosial. Jurnal Ilmu Komunikasi, Volume 17 Nomor 2, Agustus 2019, halaman 133-142

Sucahya, M. (2013). Ruang Publik Dan Ekonomi Politik Media. Lontar (Jurnal Ilmu Komunikasi), 2(2), 15-23.

Sumbada, P. A. (2017). Hirarki Pengaruh Pada Pemberitaan Pilkada DKI Jakarta di Majalah 
Tempo.

Syahputra, I. (2017). Demokrasi virtual dan perang siber di media sosial: Perspektif Netizen Indonesia. Jurnal Aspikom, 3(3), 457-475.

Tawaang, F., \& Imran, H. A. (2017). Ideologi dan Wacana Media (Studi Ideologi Media Pemilik Akun Medsos) Ideology and Media Discourse (The Media Ideology Study of Social Media Account Owner). Jurnal Studi Komunikasi Dan Media, 21(1), 59-68. http://www.kon.org/

Wijaya, T. (2019). Influence of 9 Elements of Journalism on Teknokra'S Editorial Policy. Vol 3 No 2 (2019): 6th Edition, 3(1), 1-15. https://doi.org/10.23960/metakom.v3i1.46 